\title{
Arterial pole progenitors interpret opposing FGF/BMP signals to proliferate or differentiate
}

\author{
Mary Redmond Hutson*, Xiaopei Lily Zeng, Andrew J. Kim, Emily Antoon, Stephen Harward \\ and Margaret L. Kirby
}

\begin{abstract}
SUMMARY
During heart development, a subpopulation of cells in the heart field maintains cardiac potential over several days of development and forms the myocardium and smooth muscle of the arterial pole. Using clonal and explant culture experiments, we show that these cells are a stem cell population that can differentiate into myocardium, smooth muscle and endothelial cells. The multipotent stem cells proliferate or differentiate into different cardiovascular cell fates through activation or inhibition of FGF and BMP signaling pathways. BMP promoted myocardial differentiation but not proliferation. FGF signaling promoted proliferation and induced smooth muscle differentiation, but inhibited myocardial differentiation. Blocking the Ras/Erk intracellular pathway promoted myocardial differentiation, while the PLC $\gamma$ and $\mathrm{PI} 3 \mathrm{~K}$ pathways regulated proliferation. In vivo, inhibition of both pathways resulted in predictable arterial pole defects. These studies suggest that myocardial differentiation of arterial pole progenitors requires BMP signaling combined with downregulation of the FGF/Ras/Erk pathway. The FGF pathway maintains the pool of proliferating stem cells and later promotes smooth muscle differentiation.
\end{abstract}

KEY WORDS: Cardiac stem cell, Secondary heart field, FGF, BMP, RAS/ERK, PLC $\gamma$, Smooth muscle, Myocardium, Endothelial cells, Double outlet right ventricle, Coronary arteries, Arterial pole, Chick

\section{INTRODUCTION}

Recent studies have shown that the cells that differentiate to form the primary heart tube contribute to the left ventricle and most of the atria, whereas the progenitor cells of the arterial pole, right ventricle and some of the atria are added later during looping stages by a second pool of progenitor cells that resides in the pharyngeal arches and ventral pharyngeal splanchnic mesoderm (for a review, see Dyer and Kirby, 2009b). These cardiac progenitor cells have been called the 'first and second heart fields', respectively (Meilhac et al., 2004). Both fields are subsets of the paired fields of the initial cardiogenic mesoderm in the lateral plate mesoderm (Abu-Issa and Kirby, 2007). The second heart field cells are specified to the cardiac lineage but have yet to adopt a cardiac phenotype. Expression of the LIM-homeodomain transcription factor, islet 1 (Isl1) delineates the second heart field in mouse (Cai et al., 2003). Isl 1 -null mice show a severe reduction in the atria, right ventricle and outflow tract (Cai et al., 2003).

The 'secondary' heart field (SHF) progenitors are a subset of the second heart field that contributes vascular smooth muscle and myocardium to the arterial pole (Abu-Issa and Kirby, 2007; Waldo et al., 2005). During early heart looping stages, SHF progenitors are located in the splanchnic mesoderm of the pharynx, caudal to, but continuous with, the outflow myocardium of the heart tube. The SHF-derived cells form the most distal cardiomyocytes that will be located just below the aortic and pulmonary valves, the vascular smooth muscle at the base of the aorta, and pulmonary

Division of Neonatology, Department of Pediatrics, Neonatal-Perinatal Research Institute, Box 103105, Duke University Medical Center, Durham, NC 27710, USA.

*Author for correspondence (mhutson@duke.edu)

Accepted 13 July 2010 trunk and stems of the coronary arteries (Hutson et al., 2006; Verzi et al., 2005; Waldo et al., 2005; Waldo et al., 2001; Yelbuz et al., 2003). Failure of SHF progenitors to proliferate, migrate and differentiate results in a shortened outflow tract and abnormal cardiac looping, leading to malalignment defects (Creemers et al., 2006; Hutson et al., 2006; Yelbuz et al., 2002; Yelbuz et al., 2003) such as tetralogy of Fallot and double outlet right ventricle (DORV) (Hutson et al., 2006; Waldo et al., 2001; Ward et al., 2005).

The SHF progenitor cells express the cardiac transcription factors Is11, Nkx2.5, Gata4 and Mef2c (Dyer and Kirby, 2009b). The cells in the SHF niche interpret complex signaling cues that: (1) maintain proliferation; (2) allow differentiating cells to migrate into the arterial pole; and (3) make cell fate decisions to differentiate as cardiomyocytes or (4) as vascular smooth muscle. It is not clear whether the SHF progenitors are multipotent or restricted in their cell fate at this time. Most studies on the multipotency of embryonic progenitors have been based on gene expression. In mice using $n k x 2.5$ expression as a means of cell isolation, a bipotential myocardial and smooth muscle cell precursor has been identified (Wu et al., 2006). Cells expressing the vascular endothelial growth factor receptor $F l k 1$ have been shown to give rise to cardiomyocyte, endothelial and vascular smooth muscle lineages (Kattman et al., 2006). Similarly, Isl1expressing cells were shown to differentiate into cardiac, smooth muscle and endothelial cells (Moretti et al., 2006). Recently Tbxl, a T-box transcription factor linked to DiGeorge Syndrome, has also been used to isolate multipotent cardiac progenitors, and has been shown to be important in proliferation and maintenance of the progenitor population (Chen et al., 2009).

The cardiogenic growth factors, FGF8 and BMP2/4, are present in the pharynx and outflow tract during the time cardiomyocytes are added to the heart tube from the SHF (Farrell et al., 2001; Somi et al., 2004). FGF8 is required for normal SHF development and arterial pole alignment (Abu-Issa et al., 2002; Frank et al., 2002; 
Hutson et al., 2006; Ilagan et al., 2006; Park et al., 2006; Waldo et al., 2001) but little is known about how FGF8 signaling regulates cellular behavior of the SHF progenitors. Studies in mouse and chick suggest that FGF signaling is important for SHF proliferation (Hutson et al., 2006; Park et al., 2006; Wantanabe et al., 2010). BMP $2 / 4$ expressed by the outflow myocardium are likely candidates for cardiomyocyte induction (Somi et al., 2004; Waldo et al., 2001). Exposure to noggin, a BMP antagonist, completely inhibits cardiomyocyte differentiation (Schlange et al., 2000; Schneider and Mercola, 2001; Schultheiss et al., 1997). Nothing is known about the signaling mechanisms that cause a shift from cardiomyocyte to smooth muscle production by the SHF.

In this study, we used isolated SHF mesoderm that recapitulates the embryonic developmental time course of myocardial differentiation followed by smooth muscle differentiation. Clonal analysis showed that individual SHF progenitors differentiate into myocardium, smooth muscle and endothelium with nearly $60 \%$ expressing more than one cardiovascular cell type marker, suggesting the existence of a multipotent cell. A subpopulation of Isl1-expressing cells in the SHF expresses the stem cell marker Numb, asymmetrically, suggesting that these cells are bona fide 'stem' cells. We then asked whether the pluripotent stem cells could be driven to differentiate into different cell fates by treating cultures with growth factors and inhibitors, singly or in combination. BMP2 decreased proliferation and induced myocardial differentiation, whereas FGF8 increased proliferation and decreased myocardial differentiation. Interestingly, FGF8 increased smooth muscle differentiation. Blocking either FGF receptor or Ras/Erk pathway function increased myocardial differentiation. Proliferation was decreased by inhibitors of PLC $\gamma$ or PI3 kinase/Akt pathways, but not by inhibition of Ras/Erk signaling. Embryos treated with either the PLC $\gamma$ or Ras/Erk pathway inhibitors during a crucial time in SHF development had arterial pole alignment and coronary artery patterning defects. These defects were due to premature myocardial differentiation in the case of inhibition of the Ras/Erk pathway or to decreased proliferation after inhibition of the PLC $\gamma$ pathway. These studies suggest that myocardial differentiation requires BMP signaling combined with downregulation of the FGF/Ras/Erk pathway. The FGF pathway may play an important role in maintaining the pool of undifferentiated stem cells early and promote smooth muscle differentiation later.

\section{MATERIALS AND METHODS \\ Embryos}

Fertilized Ross Hubert chick eggs (Pilgrim's Pride Hatchery, Siler City, $\mathrm{NC}$ ) were incubated for one to nine days, and Japanese quail eggs (Ozark Egg Co., Stover, MO) were incubated for one or two days. Both were maintained at $37^{\circ} \mathrm{C}$ and $70 \%$ humidity. Neural crest ablations were performed as previously described (Waldo et al., 1996).

\section{SHF explant culture}

The secondary heart field mesoderm was isolated from HH14 (Hamburger and Hamilton, 1951) chick embryos. Specifically the ventral mesoderm located between the outflow tract and inflow tract was dissected away from the body wall (see Fig. S1 in the supplementary material). This mesoderm with the underlying ventral pharyngeal endoderm was briefly digested in pancreatin and trypsin as previously described (Dyer and Kirby, 2009a), and the two layers were gently separated using fine dissecting needles. The secondary heart field mesoderm was placed in $2 \%$ FBS in L15 media until plating. The secondary heart field mesoderm is easily distinguished from the endoderm because the endoderm curls while the secondary mesodermal layer remains flat. Explants were cultured on fibronectin (FN)-coated glass slides (BD Sciences, San Jose, CA) in DMEM with $2 \%$ FBS supplemented with various combinations of growth factors and/or inhibitors as described in the results. Recombinant (r)FGF8b (R\&D Systems), rBMP2 (R\&D Systems, Minneapolis, MN) and Noggin (R\&D Systems, Minneapolis, MN) were reconstituted according to the manufacturer's recommendations. The PLC $\gamma$ inhibitor U73122 (ENZO Life Sciences, Plymouth Meeting, PA), the MEK inhibitor U0126 (Promega, Madison, WI), the PI3K inhibitor LY294002 (Cell Signaling Technologies, Danvers, MA) and the FGF receptor inhibitor SU5402 (Calbiochem, San Diego, CA) were dissolved according to the manufacturer's directions. Control cultures also contained $0.1 \%$ DMSO to control for vehicle effects.

\section{Antibodies and immunohistochemistry}

The following primary antibodies were used: MF20, QH1 and Is11 (Developmental Studies Hybridoma Bank, Iowa City, IA); pHH3 (Millipore, Temecula, CA); anti-BrdU (Roche, Madison, WI); SM22 and Flk1 (Abcam, Cambridge, MA); smooth muscle light chain kinase (SMLCK) and smooth muscle actin (SMA) (Sigma-Adrich, St Louis, MO); Nkx2.5 (Santa Cruz, Santa Cruz, CA); Numb and Transitin (a generous gift from Dr Yoshio Wakamatsu, Tohoku University, Japan). Antibodies were visualized with AlexaFluor 350, 488 or 568 (Invitrogen, Molecular Probes, Carlsbad, CA). Nuclei were visualized with Hoechst (Invitrogen, Molecular Probes). Immunohistochemistry was carried out as reported previously (Dyer and Kirby, 2009a; Waldo et al., 1996). DAF-2DA (Calbiochem, San Diego, CA), a membrane-permeable compound that detects the presence of NO in vivo (Kojima et al., 1998), labels chick arterial pole smooth muscle (Grimes et al., 2006) and endothelial cells (Nakatsubo et al., 1998). SHF cultures were grown overnight with $10 \mu \mathrm{m}$ DAF-2DA added to the culture media.

\section{In vitro secondary heart field proliferation and differentiation assay}

After 24-48 hours in culture, SHF explants in the various treatment groups were immunostained with MF20, phosphoHistone $\mathrm{H} 3$ (pHH3) and/or SMLCK, as well as the nuclear marker Hoechst. Binary images of each stain were taken of the entire explant. The image analysis software, Acapella (Perkin Elmer, Waltham, MA), was used to count the total number of nuclei and the number of $\mathrm{pHH}^{+}$and $\mathrm{MF}^{+} 0^{+}$cells. The percent of differentiation and proliferation was calculated for each explant and a minimum of seven explants was counted in each treatment group. To determine whether the percent differentiation and proliferation met statistical significance $(P \leq 0.05)$, we used the Kruskal-Wallis test.

\section{Clonal cultures}

Approximately 40 SHF explants were isolated as above from chick or quail embryos and placed in $100 \mu \mathrm{l}$ of $0.25 \%$ trypsin for 15 minutes. After gentle tituration, an equal volume of DMEM with 5\% FBS was added to stop the digestion. The cells were pelleted and resuspended in DMEM with $20 \%$ FBS. The cells were passed through a $40 \mu \mathrm{m}$ filter to remove cell clumps. Approximated 60,000 cells were recovered after the isolation procedure. Cells were plated at clonal density in 96-well plates and cultured in DMEM with $20 \%$ FBS for 5 days. The single SHF cells did not need to be grown on feeder layers. On day 5 , the number of wells with spontaneously beating cells was documented. The cells were fixed in $4 \%$ PFA or methanol followed by immunohistochemistry for myocardial, (MF20) smooth muscle (SMA and SM22) and endothelial cell markers (QH1).

\section{In ovo inhibitor studies}

DMSO vehicle control, the Mek inhibitor and the PLC $\gamma$ inhibitor were applied to HH11 embryos as previously described (Hutson et al., 2006). For the proliferation studies, control and treated embryos were exposed to BrdU at HH 16 for 1 hour, processed for immunohistochemistry and counted as described previously (Hutson et al., 2006). ANOVA and Student's $t$-test was used to determine statistical significance.

Analysis of arterial pole alignment and Hematoxylin and Eosin staining at HH35 (embryonic day 9) was carried out as previously described (Hutson et al., 2006). Some day 9 hearts from control and Mek inhibitortreated embryos were fixed in 4\% PFA and stained for SM22 to study coronary artery stem anatomy. 


\section{Statistical analysis}

Microsoft Excel and R statistical software were used for statistical analysis. In all analyses, $P \leq 0.05$ was used to indicate statistical significance

\section{RESULTS}

\section{SHF mesoderm spontaneously differentiates into cardiac cell lineages}

For the current studies, we isolated the SHF mesoderm from its adherent endoderm to eliminate an uncontrolled source of signaling factors. These 'pure' SHF mesoderm explants differentiated a subpopulation of spontaneously beating myocardial cells when grown 24-48 hours in culture. After 48 hours in culture, a few cells $(<10$ cells) expressed smooth muscle light chain kinase (SMLCK), an early marker of smooth muscle differentiation (data not shown). To follow smooth muscle differentiation in 'real time' the SHF explants were exposed to the nitrous oxide sensor DAF2DA, a marker of vascular smooth muscle and endothelial cells. Elongated smooth muscle cells were observed between 72 and 96 hours in culture (Fig. 1A,B; data not shown). In addition to the spindleshaped smooth muscle cells, some of the DAF-2DA-positive cells showed a more rounded morphology, suggestive of endothelial cells (Fig. 1C). Interestingly, most of the DAF-2DA-positive cells (rounded and spindle shaped) were adjacent to the MF-20 cells, recapitulating components of the myocardial/smooth muscle junction lined by endothelial cells observed at the arterial pole in vivo (Fig. 1A-C) (Grimes et al., 2006). We confirmed the differentiation of smooth muscle adjacent to differentiated myocardium using SMA, SMLCK and SM22 (data not shown). The early appearance of myocardial cells followed later by smooth muscle differentiation in vitro coincided with the in vivo timeline of myocardial and smooth muscle differentiation.

To determine whether the SHF represents multipotent progenitors, we cultured dissociated SHF cells at clonal density. After 5 days, $86 \%$ of the wells contained one or more live cells. Of these, nearly a quarter of the wells $(20 / 83)$ had spontaneously contracting cells prior to fixation. Interestingly, the beating cells were observed in tightly packed clusters of 10 or more cells (Fig. 1J). All the wells were immunostained with MF20 and one out of two smooth muscle markers, SM22 or SMA (see Table S1 in the supplementary material). Fifty-seven percent (47/83) of the wells had MF20 and/or smooth muscle marker-positive cells, including the wells that contained spontaneously beating cells (Fig. 1D,E,G,H,J). Most of the larger clones ( $>10$ cells) expressed both myocardial and smooth muscle markers. Ten percent $(8 / 83)$ of the wells contained only MF20-positive cells, and these were either single cells or small clusters of two to three cells (Fig. 1D,G). Thirteen percent $(11 / 83)$ of the clones expressed only the smooth muscle markers (Fig. 1E,H). Eight percent (7/83) of the clones expressed no muscle markers. In some of the wells with only MF20-positive or smooth muscle marker-positive cells, other cells did not express muscle markers and these cells along with the wells that contained no muscle markers may represent an endothelial cell lineage or an undifferentiated progenitor cell (Fig. 1G,I,J, and data not shown).

To determine whether the SHF contained endothelial progenitors, we repeated the clonal analysis experiment using SHF cells isolated from quail because the quail antibody, QH1, is an unequivocal early marker for endothelial cells. The quail cells had similar viability after 5 days in culture with $75 \%(72 / 96)$ of the wells containing living cells (see Table S2 in the supplementary material). Four percent (3/72) of the clones were QH1 positive, $17 \%(12 / 72)$ were MF20-only positive, $18 \%(13 / 72)$ were SMA
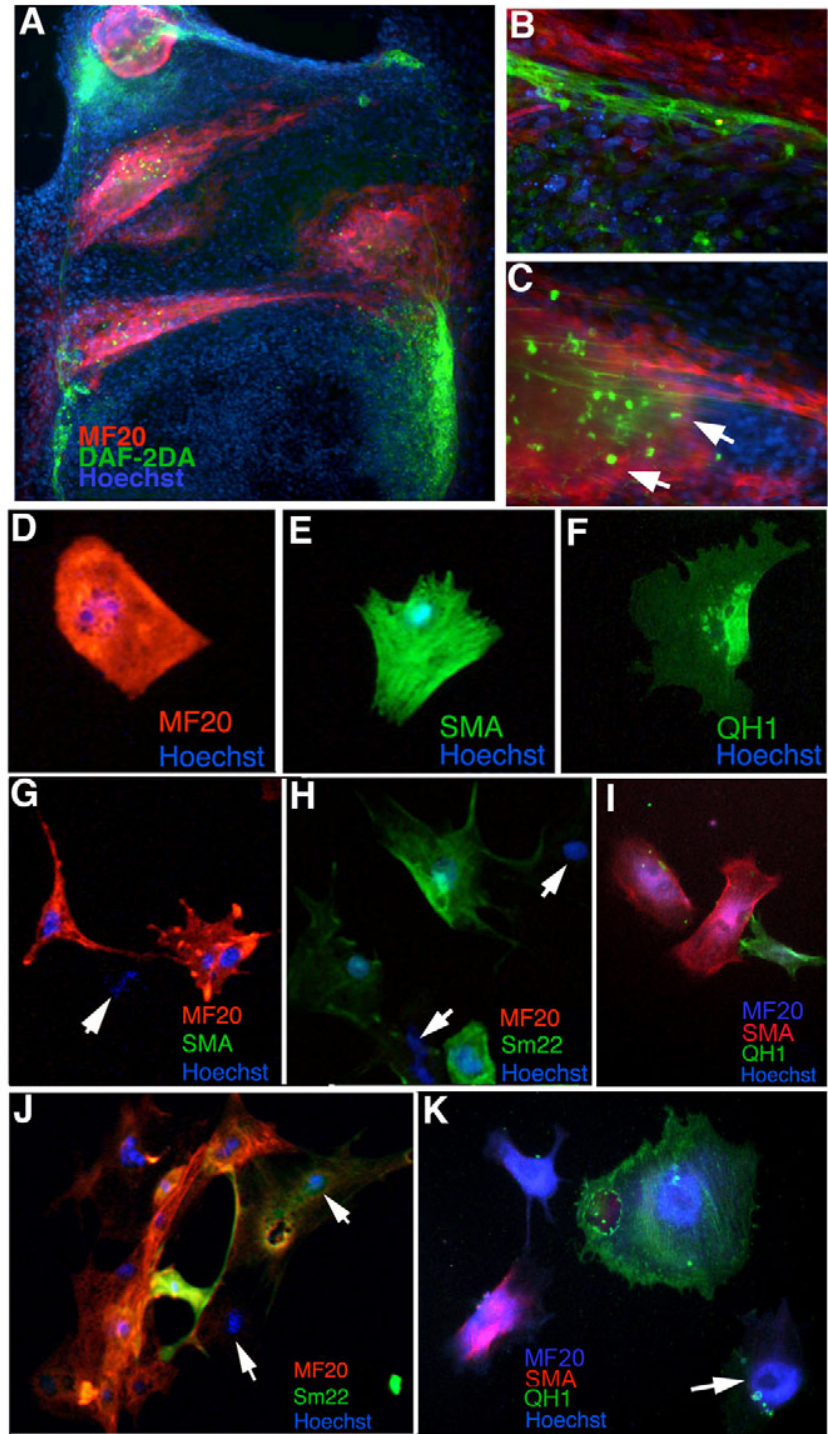

Fig. 1. Clonal analysis of the secondary heart field.

(A-C) Secondary heart field progenitors differentiate into beating myocardium (red), smooth muscle (elongated green) and endothelial cells (rounded green) after 96 hours in culture. B and C are enlarged regions from A. (D-K) Clonal analysis shows the that SHF contains a multipotent progenitor cell that is capable of differentiating into myocardium $(D, G, J, K)$, smooth muscle $(E, H-K)$ and endothelial cells $(\mathrm{F}, \mathrm{I}, \mathrm{K})$. Tripotency is demonstrated in $\mathrm{K}$ with a clone expressing multiple cardiac cell lineage markers. Blue labels the nuclei in all the cells and the nuclei plus the cytoplasm in the MF20-positive cell (blue arrowhead). Arrows indicate nuclei expressing no differentiation markers.

positive and $17 \%(12 / 72)$ were positive for all three markers (data not shown and Fig. 1F,I,K). Interestingly, as in the chick experiments there were cells in the clone that did not express any of the markers (arrow in Fig. 1J) and may represent an undifferentiated progenitor cell. Five percent (4/72) of the clones expressed no differentiation markers. Endothelial cells were identified in wells that were also SMA positive but MF20 negative in $14 \%(10 / 72)$ of the clones (Fig. 1I). Furthermore, 25\% (18/72) of the clones were positive for myocardial and smooth muscle markers but negative for the endothelial cell marker (data not 

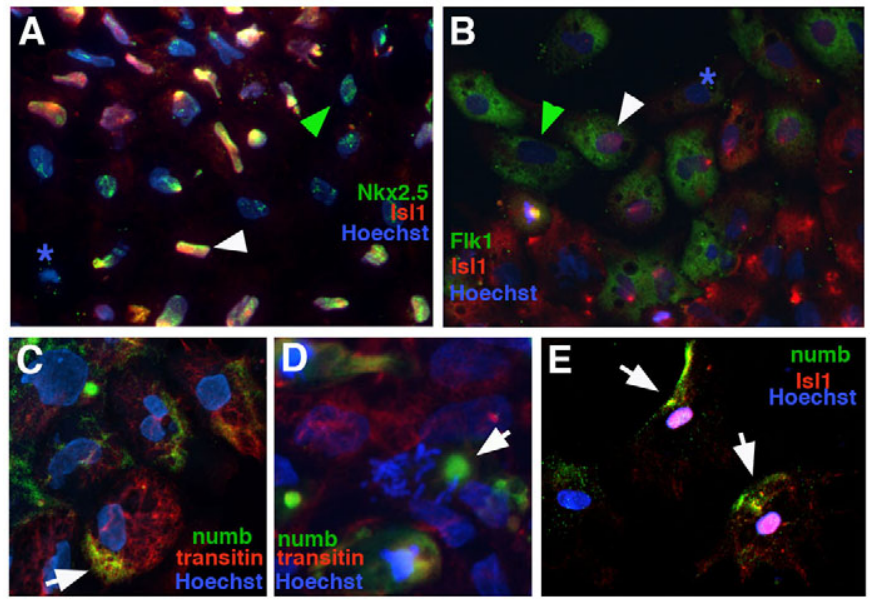

Fig. 2. Identification of stem cells in the SHF. (A) Cells doubly positive for Isl1 and Nkx2.5 (white arrowhead) represent a myocardial and smooth muscle lineage. (B) Cells doubly positive for IsI1 and Flk1 (white arrowhead) represent a smooth muscle and endothelial cell lineage. Cultures are a mixed population, with some cells expressing only one marker (green arrowhead) or no marker (blue asterisk). (C-E) Asymmetrical localization of Numb (green, white arrows) in SHF cells suggests existence of a stem cell population [C,D are also stained for transitin, a type IV intermediate filament protein that has been shown to co-localize with Numb (Wakamatsu et al., 2007)]. (D) Cell with condensed chromatin and asymmetric localization of Numb. (E) Asymmetric localization of Numb in Isl1-expressing cells.

shown). These results show that HH14 SHF contains multipotential cells that are capable of differentiating into myocardium, smooth muscle and endothelium.

\section{Asymmetric localization of Numb marks a self-renewing stem cell in the SHF}

Recent studies have shown that a multipotent cardiac progenitor isolated from ES cells has the transcriptional signature Is $11^{+} / \mathrm{Nkx} 2.5^{+} / \mathrm{Flk} 1^{+}$and can give rise to cardiovascular lineages (Moretti et al., 2006). We tested SHF cells for a similar transcriptional signature. After 24 hours in culture, SHF cells were doubly positive for Is11 and Nkx2.5 (Fig. 2A), representing a myocardial and smooth muscle lineage or a multipotent progenitor. Some cells expressed only Nkx2.5, suggesting the myocardial lineage. In another set of explants, cells were doubly positive for Is $11^{+}$and $\mathrm{Flk}^{+}$expression (Fig. 2B), representing smooth muscle/endothelial cell lineages. Some cells expressed only flk1, indicating differentiated endothelial cells. These results show that the SHF contains cells with the gene expression signatures of multipotent cardiovascular cells.

One strategy by which stem cells can accomplish self-renewal is asymmetric cell division, whereby a stem cell divides to generate one daughter with a stem-cell fate (self-renewal) and one daughter that will differentiate. Numb is an evolutionarily conserved protein that plays crucial roles asymmetric cell division, and in cell fate choice in invertebrate and vertebrate neuroepithelial stem cells (for a review, see Gulino et al., 2010). To determine whether the SHF progenitors were capable of asymmetric cell division, we stained SHF cultures for Numb. Asymmetric localization of Numb was detected in 21\% (92/459) of Is11 ${ }^{+}$SHF cells (Fig. 2C-E). Not all Numb-expressing cells had asymmetric localization, and not all Isl ${ }^{+}$ cells expressed Numb. Because Numb is a cytoplasmic adapter protein, it must be anchored to the cytoskeleton in order localize asymmetrically. Transitin, a type IV intermediate filament, has been shown in mitotic neuroepithelial cells to interact directly with Numb and provide an anchor site for Numb localization (Wakamatsu et al., 2007). We stained SHF explants for both Numb and Transitin, and found co-localization (Fig. 2C,D), suggesting cardiac multipotent progenitors share a similar mechanism for asymmetric division with neuroepithelial stem cells.

\section{FGF8 signaling promotes proliferation and depresses myocardial differentiation}

FGF8 is known to be required for normal SHF development and arterial pole alignment (Abu-Issa et al., 2002; Frank et al., 2002; Hutson et al., 2006; Ilagan et al., 2006; Park et al., 2006; Waldo et al., 2001) but little is known about how it regulates cellular behavior of the SHF progenitors. We used SHF explants to test the how FGF8 influences proliferation and differentiation. The explants were treated with increasing concentrations of FGF8 or with the FGF receptor blocker SU5402 for 24 hours. Both concentrations of FGF8 (5 and $10 \mathrm{ng} / \mathrm{ml}$ ) significantly increased SHF pHH3 expression $(P \leq 0.003)$ (Fig. 3A). Inhibition of FGF signaling with SU5402 significantly decreased proliferation when compared with controls $(P=0.01)$ and with the $2.5 \mathrm{ng} / \mathrm{ml}$ and 5 ng/ml FGF8-treated groups $(P<0.001)$. FGF8 treatment significantly decreased myocardial differentiation at the $5 \mathrm{ng} / \mathrm{ml}$ concentration ( $P=0.004$, Fig. 3B). Inhibition of FGF signaling with SU5402 increased differentiation compared with controls $(P=0.014)$ and all FGF8 treatment groups $(P \leq 0.03)$. These data suggest that FGF signaling may actively inhibit myocardial differentiation and promote proliferation in the cardiac progenitors of the SHF. Furthermore, the ability of FGF to regulate these behaviors is concentration dependent.

\section{BMP regulates myocardial differentiation in SHF explants}

Proximity of the outflow myocardium is required for the SHF progenitors to differentiate into cardiomyocytes (Somi et al., 2004; Waldo et al., 2001). The outflow myocardium expresses BMP2/4, which are likely candidates for cardiomyocyte induction (Somi et al., 2004; Waldo et al., 2001). To determine the effect of BMP signaling on proliferation and differentiation of isolated SHF mesoderm, we exposed SHF explants to increasing concentrations of BMP2. Moderate to high doses of BMP resulted in decreased proliferation compared with controls (Fig. 3C, $P \leq 0.0001$ ). Not surprisingly all concentrations of BMP2 increased myocardial differentiation (Fig. 3D, $P \leq 0.004)$. Each increase in BMP2 dose increased differentiation $(P \leq 0.02)$. The decrease in proliferation and increase in differentiation was blocked by the BMP antagonist noggin (Fig. 3C).

\section{FGF signaling modulates BMP signaling in SHF explants}

Previous studies of differentiating first heart field cells suggest that a balance of BMP and FGF signaling is required for to promote cardiomyocyte differentiation from cardiac progenitors (Barron et al., 2000). We exposed the SHF explants to combinations of low and high doses of BMP2 and FGF8 (Fig. 3E,F). Low doses of both BMP2 $(25 \mathrm{ng} / \mathrm{ml})$ and FGF8 $(2.5 \mathrm{ng} / \mathrm{ml})$ significantly increased proliferation compared with control explants or with explants treated with BMP2 alone $(P \leq 0.005)$. Proliferation levels were similar to treatment with $2.5 \mathrm{ng}$ FGF8 alone. Treatment with low dose BMP2 (25 ng/ml) and higher FGF8 (5 ng/ml) dose also 
A

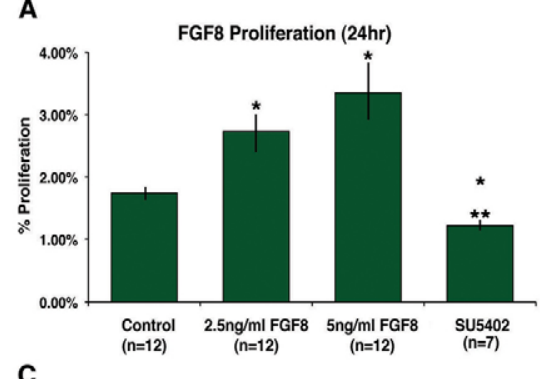

C

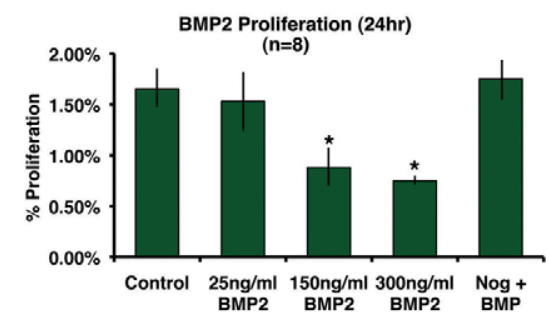

E

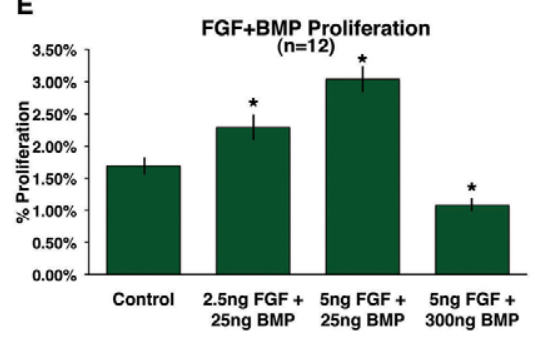

B

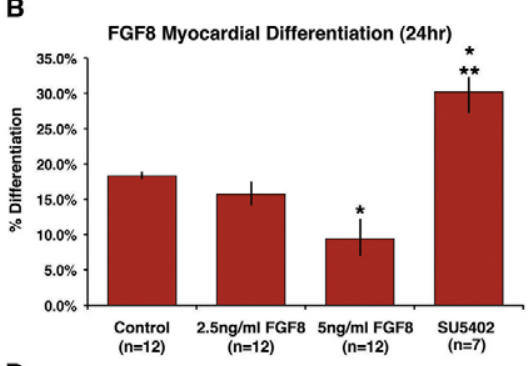

D

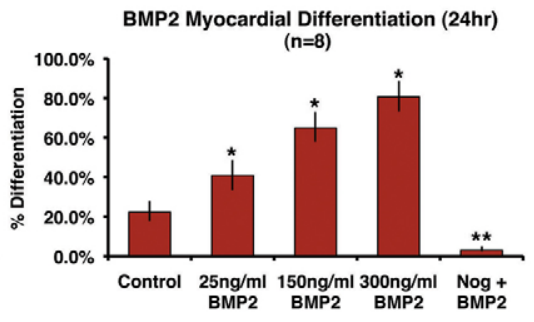

$\mathbf{F}$

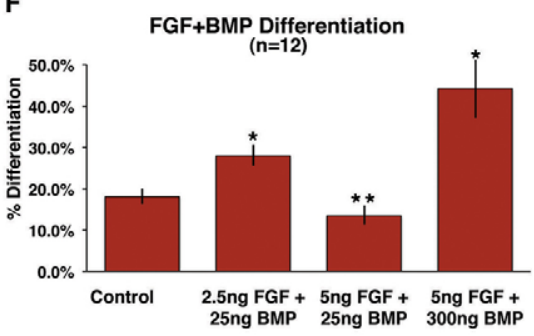

Fig. 3. SHF explants cultured for 24 hours with FGF8 or BMP2, alone or in combination, and analyzed for proliferation (pHH3) or myocardial differentiation (MF20). (A) Low concentrations of FGF8 (2.5-5.0 ng/ml) significantly increased SHF proliferation (* $P \leq 0.003$ compared with control). SU5402 treatment significantly decreased proliferation when compared with controls ( $\left.{ }^{*} P=0.01\right)$ and $2.5 \mathrm{ng}$ and $5.0 \mathrm{ng}$ FGF8-treated groups ( ${ }^{*} P \leq 0.008$ ). (B) FGF8 treatment decreased myocardial differentiation with the $5 \mathrm{ng} / \mathrm{ml}$ dose $\left({ }^{*} P=0.004\right)$. SU5402 significantly increased differentiation when compared with controls $\left({ }^{*} P=0.014\right)$ and all FGF8 treatment groups $(* * P \leq 0.03)$. (C) Increasing concentrations of BMP decreased proliferation compared with controls ( $\left.{ }^{*} P \leq 0.0001\right)$. This effect was negated by Noggin exposure ( $n=8$ for each treatment group). (D) Increasing concentrations of BMP increased myocardial differentiation compared with control ( $\left.{ }^{*} P \leq 0.004\right)$. This effect was inhibited by Noggin $(* * P<0.0001)$. Each increase in BMP2 dose significantly increased differentiation ( $\left.{ }^{*} P \leq 0.02\right)$ ( $n=8$ for each treatment group). (E) FGF8 (2.5 ng/ml) plus $25 \mathrm{ng} / \mathrm{ml}$ BMP2 treatment increased proliferation compared with controls ( $\left.{ }^{*} P=0.003\right)$. Treatment with low dose BMP2 (25 ng/ml) and high FGF8 (5 ng/ml) dose significantly increased proliferation compared with control ( $\left.{ }^{*} P=0.0001\right)$. Proliferation levels were significantly reduced when explants were cultured with $5 \mathrm{ng} / \mathrm{ml} \mathrm{FGF8}$ and $300 \mathrm{ng} / \mathrm{ml} \mathrm{BMP2}\left({ }^{*} P=0.0001\right)$ ( $n=12$ for each treatment group). (F) $25 \mathrm{ng} / \mathrm{ml} \mathrm{BMP2} \mathrm{plus} 2.5 \mathrm{ng} / \mathrm{ml} \mathrm{FGF8} \mathrm{treatment}$ did not increase differentiation compared with controls and FGF8. Myocardial differentiation was significantly decreased in explants grown with $5 \mathrm{ng} / \mathrm{ml} \mathrm{FGF8}$ and $25 \mathrm{ng} / \mathrm{ml} \mathrm{BMP2} \mathrm{(*P=0.0001)} \mathrm{Myocardial} \mathrm{differentiation} \mathrm{was} \mathrm{significantly} \mathrm{increased} \mathrm{in} \mathrm{explants} \mathrm{grown} \mathrm{in} 300 \mathrm{ng} / \mathrm{ml}$ BMP and $5 \mathrm{ng} / \mathrm{ml} \mathrm{FGF8} \mathrm{(}{ }^{*}=0.003$ ) compared with controls ( $n=12$ for each treatment group).

significantly increased proliferation compared with control or low dose BMP2 alone $(P<0.0001$, compare Fig. 3E with 3C). In these FGF+BMP combination experiments, proliferation levels were only significantly reduced when explants were cultured with the high $300 \mathrm{ng} / \mathrm{ml}$ BMP2 concentration $(P<0.0003)$. However, proliferation was still higher than with BMP2 treatment alone $(P=0.05)$. Explants treated with $25 \mathrm{ng} / \mathrm{ml} \mathrm{BMP} 2$ plus $2.5 \mathrm{ng} / \mathrm{ml}$ of FGF8 showed no significant difference in differentiation compared with control explants but differentiation was increased compared with $2.5 \mathrm{ng} / \mathrm{ml} \mathrm{FGF8}$ alone $(P<0.01)$. However, differentiation was significantly diminished compared with $25 \mathrm{ng} / \mathrm{ml}$ BMP treatment alone $(P=0.0002$, compare Fig. 3D with $3 \mathrm{~F})$. Interestingly, the pro-differentiation effect of BMP was completely abrogated in explants grown with high dose FGF8 and low dose BMP2 $(P=0.0001)$. Myocardial differentiation was significantly increased in explants grown in high concentrations of both BMP $(300 \mathrm{ng} / \mathrm{ml})$ and FGF8 $(5 \mathrm{ng} / \mathrm{ml})$ compared with controls or 5 ng/ml FGF8 treatment alone $(P \leq 0.001)$. However, differentiation levels were decreased by nearly $50 \%$ compared with BMP2 treatment alone $(P=0.005$ compare Fig. $3 \mathrm{D}$ with $3 \mathrm{~F})$. These results show that FGF inhibits BMP-induced differentiation in favor of progenitor proliferation.

\section{PLC- $\gamma$ and AKT pathways regulate proliferation while the Ras pathway inhibits myocardial differentiation}

FGF ligand binding triggers intracellular transduction cascades, including Ras-dependent and Ras-independent pathways. To determine the role of the intracellular pathways on differentiation and proliferation in the SHF, we exposed explants to pathway specific inhibitors (Fig. 4A,B). Inhibiting the Ras/Erk pathway using the Mek inhibitor U0126 had no effect on proliferation, but significantly increased myocardial differentiation $(P=0.03)$. Inhibition of the AKT pathway with the PI3K inhibitor LY 294002 
A FGF Pathway Inhibitors (24hr)
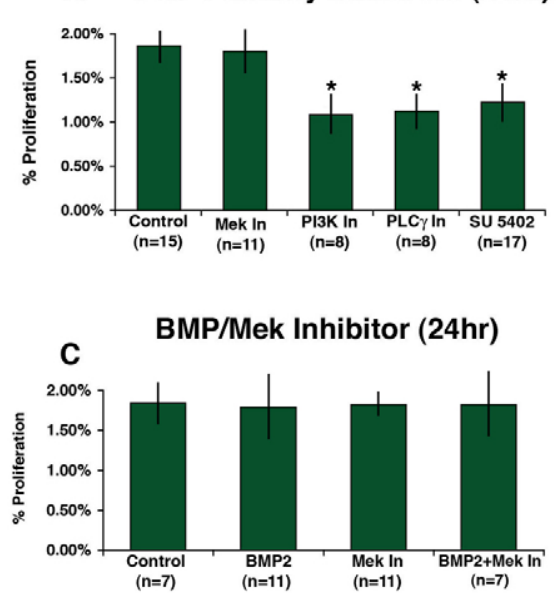

B FGF Pathway Inhibitors (24hr)
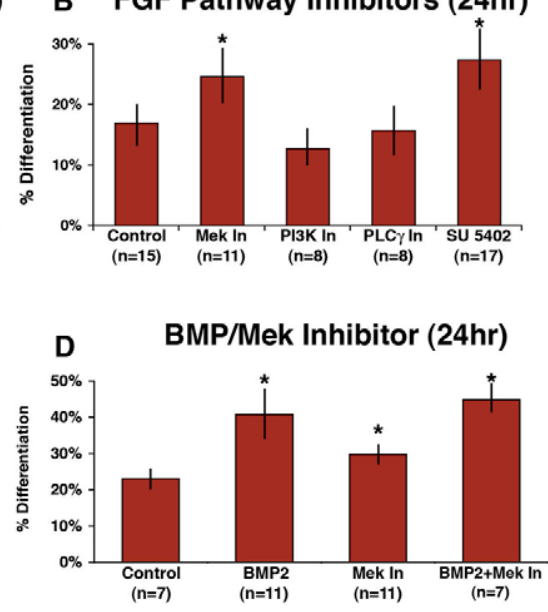

Fig. 4. Dissecting the role of the FGF intracellular signaling pathways in SHF explants grown for 24 hours. (A,B) Inhibiting of the Ras/Erk pathway using the MEK inhibitor had no effect on proliferation (A) but significantly increased myocardial differentiation (B) compared with controls $\left(\mathrm{B},{ }^{*} P=0.03\right)$. Inhibition of the AKT pathway with the PI3K inhibitor decreased proliferation $\left(A,{ }^{*} P=0.001\right)$ but had no effect on differentiation. Inhibition of the PKC pathway with the PLC $\gamma$ inhibitor decreased proliferation ( $\left.A,{ }^{*} P=0.001\right)$ but had no effect on differentiation. Blocking the FGF signaling with SU5402 decreased proliferation ( $\left.\mathrm{A},{ }^{*} P=0.003\right)$ in the same way as the PI3K and PLC- $\gamma$ inhibitors, and increased differentiation ( $\mathrm{B}$; $\star P=0.02)$ in the same way as the MEK inhibitor. $(\mathbf{C}, \mathbf{D})$ Treatment with low dose BMP2 $(25 \mathrm{ng} / \mathrm{ml})$ plus the MEK inhibitor did not affect proliferation. Combining BMP2 and the Mek inhibitor significantly increased myocardial differentiation compared with controls (* $P=0.001)$ but was not significantly increased compared with BMP alone.

decreased proliferation $(P=0.001)$ but had no effect on differentiation. Inhibition of the PKC pathway with the PLC $\gamma$ inhibitor $\mathrm{U} 73122$ decreased proliferation $(P=0.001)$ but had no effect on differentiation. Blocking FGF receptor signaling with SU5402 decreased proliferation $(P=0.003)$, as did the PI3K and PLC $\gamma$ inhibitors, and increased differentiation $(P=0.02)$, as did the Mek inhibitor (Fig. 4A,B). Thus, we were able to uncouple the intracellular signaling pathways that differentially regulate proliferation and differentiation. This suggests that the Ras/Erk pathway inhibits differentiation of SHF cardiac progenitors, and that the PI3K/Akt and PKC/PLC $\gamma$ pathways regulate proliferation.

To determine whether the Mek pathway could synergize with BMP, we treated SHF cultures with BMP and the Mek inhibitor. Treatment with low dose BMP2 $(25 \mathrm{ng} / \mathrm{ml})$ plus Mek inhibitor dramatically increased myocardial differentiation but did not affect proliferation, further supporting idea that the Ras/Erk signaling regulates differentiation but not proliferation (Fig. 4C,D).

\section{FGF signaling promotes smooth muscle differentiation in the SHF explants}

Because the SHF also contains smooth muscle progenitors, we determined the effect of FGF8 and BMP2 exposure on smooth muscle differentiation. Smooth muscle differentiation was increased in the SHF cultures grown with $5 \mu \mathrm{g} / \mathrm{ml}$ and $10 \mu \mathrm{g} / \mathrm{ml}$ of FGF8 when compared with control cultures $(P<0.05)$, whereas SHFs cultured in BMP2 showed little or no smooth muscle differentiation (Fig. 5). The lack of smooth muscle differentiation in the BMP2-treated cultures is not surprising in that nearly $80 \%$ of the SHF had differentiated into myocardium. Furthermore, no smooth muscle was observed in the cultures treated with the MEK inhibitor (Fig. 5C). As in the 24 hour cultures, FGF8-treated explants have significantly less myocardium than controls $(P=0.04)$ or BMP2-treated cultures $(P=0.001)$ (Fig. 5E). This suggests that FGF signaling may play a role in smooth muscle differentiation and that the differentiation is dependent on the Ras/Erk pathway.

\section{Inhibition of Ras/Erk and PLC- $\gamma$ pathways disrupts heart looping and arterial pole alignment}

Disruption of SHF proliferation or differentiation causes abnormal heart looping leading to arterial pole defects (Hutson et al., 2006; $\mathrm{Xu}$ et al., 2004). Because the disruption of Ras/Erk or PLC $\gamma$ signaling caused defects in differentiation and proliferation, respectively, in vitro, we wanted to determine the consequences of inhibiting the Ras/Erk or the PLC $\gamma$ intracellular pathways on heart looping and arterial pole alignment in vivo. HH11 embryos were treated with $10 \mu \mathrm{M}$ PLC $\gamma$ or MEK inhibitor. At HH16, abnormal heart looping was observed in $60 \%$ of embryos in both treatment groups ( $n=8$ for each group) (Fig. $6 \mathrm{~A}-\mathrm{C}$ ).

Next, we determined the effect of inhibiting the Ras/Erk or the PLC $\gamma$ intracellular pathways on arterial pole alignment at day 9. In both treatment groups, $50 \%$ of the animals treated with either the MEK (three out of six) or PLC $\gamma$ (four out of seven) inhibitor had arterial pole defects, including DORV (Fig. 6E,F,H,I) and ventricular septal defects (data not shown). Four out of seven embryos treated with the low dose of PLC $\gamma$ inhibitor had DORV with either pulmonary or aortic stenosis. More severe defects were observed in hearts from embryos treated with a high dose $(20 \mu \mathrm{M})$ of the PLC $\gamma$ inhibitor, including two out of seven hearts with double inlet left ventricle (see Fig. S2 in the supplementary material). All embryos treated with the high $20 \mathrm{uM}$ dose of the MEK inhibitor died before day 9. These data suggest that disrupting the Ras/Erk and PLC $\gamma$ pathways during early stages of SHF development leads to arterial pole defects. Furthermore, the cardiac phenotypes observed in the embryos treated with either inhibitor were similar to those we observed in our previously reported studies using SU5402 (Hutson et al., 2006).

In previous studies, we have shown that neural crest ablation resulted in FGF8 'over-signaling' in the pharynx and caused increased proliferation of the SHF progenitors coupled to abnormal looping (Hutson et al., 2006). This resulted in outflow alignment defects in addition to the persistent truncus arteriosus (PTA), owing 

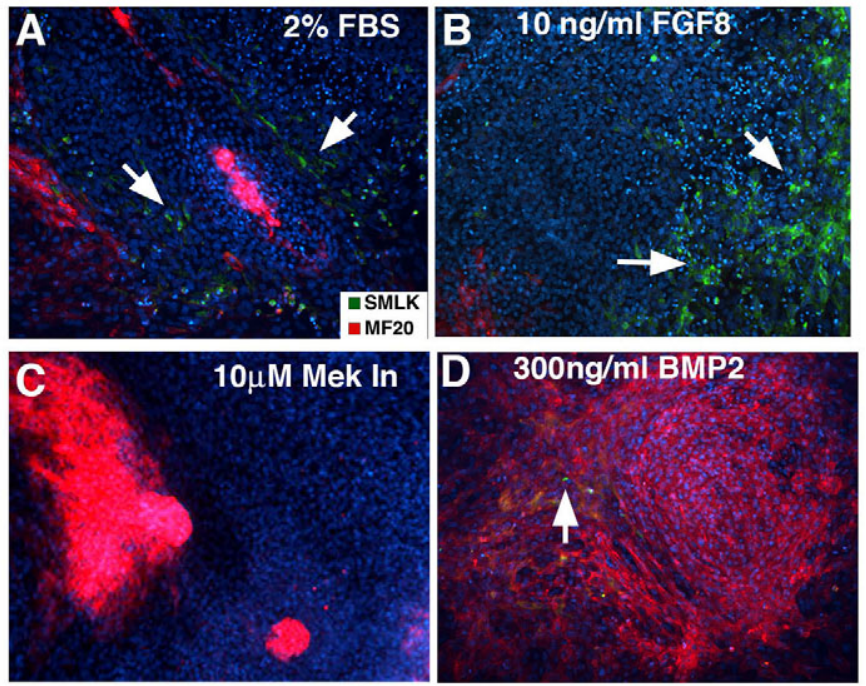

\section{E}

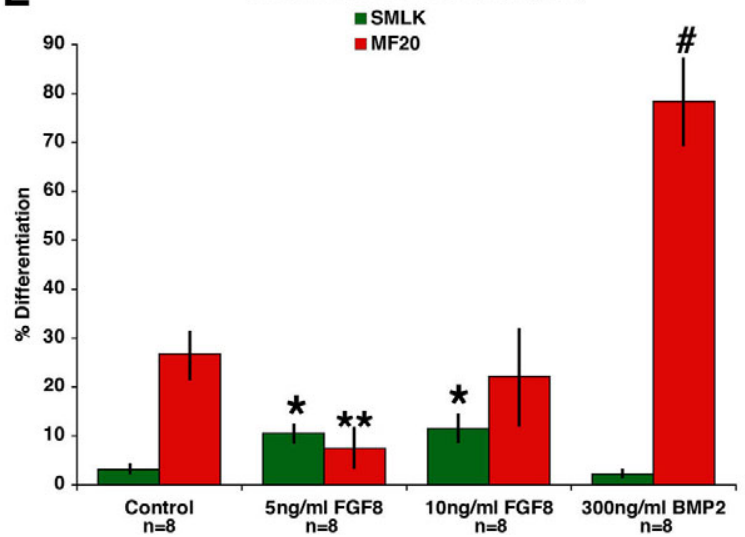

Fig. 5. FGF8 promotes smooth muscle differentiation after $\mathbf{4 8}$ hours in culture. (A-D) SHF explants grown for 48 hours and stained for MF20 (red) and SMLK (green). (A) Control culture grown in 2\% FBS. (B) SHF cultures grown with $10 \mu \mathrm{g} / \mathrm{ml}$ of FGF8 showing increased smooth muscle differentiation (green) compared with control. (C) SHF grown for 48 hours with Mek inhibitor. (D) Forty-eight-hour culture grown with BMP2. Arrows indicate differentiating smooth muscle cells. (E) FGF8-treated SHF explants had significantly more smooth muscle (green) compared with control or BMP2-treated cultures ( $\left.{ }^{*} P \leq 0.05\right)$. FGF8-treated explants $(5 \mathrm{ng} / \mathrm{ml})$ had significantly less myocardium than did controls ( $* * P=0.04$ ) or BMP2-treated cultures ( $* * P=0.001$ ). After 48 hours, nearly all of the BMP2-treated culture differentiated into myocardium (\#).

to the absence of the cardiac neural crest-derived outflow septum. We were able to rescue the alignment defects (but not the septation defect) by abrogating FGF signaling using SU5402 or a FGF8 function-blocking antibody. To determine whether the inhibition of MEK and/or PLC $\gamma$ pathway could also rescue arterial pole alignment defects caused by FGF over-signaling, we treated neural crest-ablated embryos with either the MEK or the PLC- $\gamma$ inhibitor and examined cardiac looping and arterial pole alignment. In both the Mek and PLC $\gamma$ inhibitor-treated embryos, the looping defects were rescued in $60 \%$ of neural crest-ablated embryos, suggesting normalization of FGF signaling and normal addition of SHF-derived myocardium to the outflow tract (data not shown). Similar to extracellular inhibitors in the previous studies, both intracellular
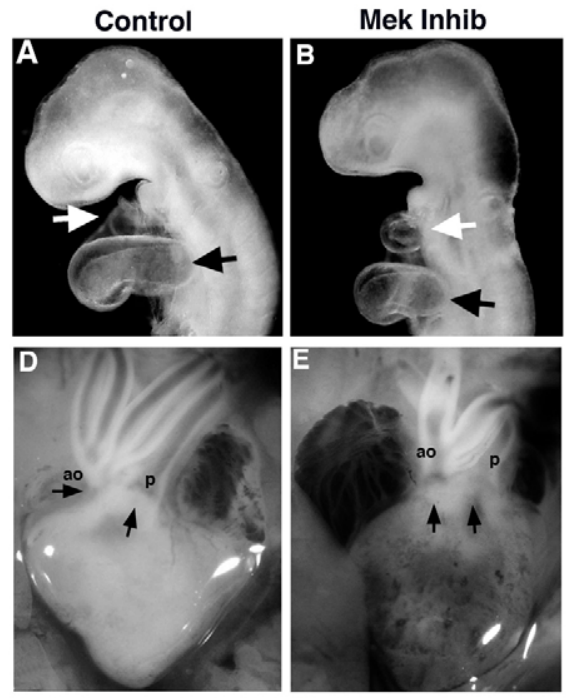

PLC $\gamma$ Inhib
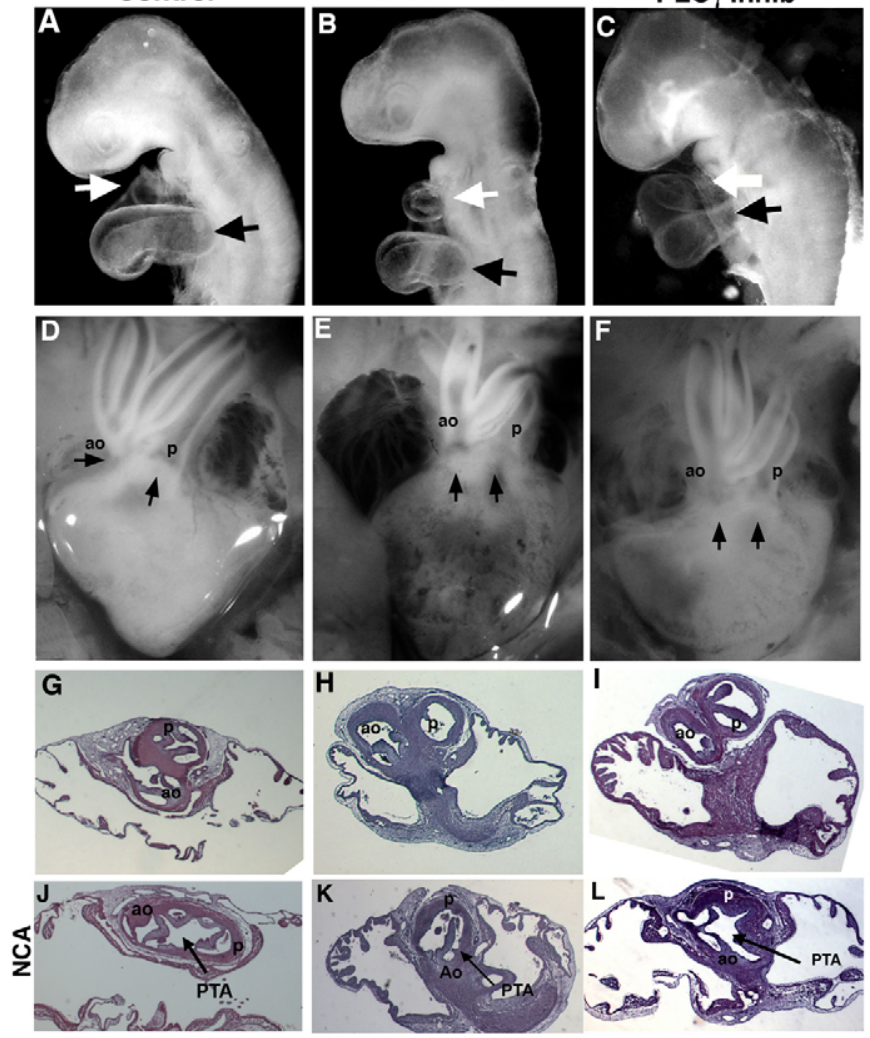

Fig. 6. Inhibition of Ras/Erk and PLC $\gamma$ pathways disrupts arterial pole alignment. (A-C) Inhibitor treatment disrupted heart looping. Left side view of $\mathrm{HH} 16$ embryos after 24 hour exposure to either vehicle control (A), $10 \mu \mathrm{M}$ of MEK inhibitor (B) or $10 \mu \mathrm{M}$ of the PLC $\gamma$ inhibitor (C). Abnormal heart looping was observed in both inhibitor treatment groups. Normally, the outflow limb (white arrows) is partially obscured by the inflow limb (black arrows). (D-F) Arterial pole alignment in heart from day 9 embryos was disrupted after inhibitor treatment. (D) Control heart showed normal alignment (arrows) of the aorta (ao) and pulmonary trunk (p). Hearts from MEK inhibitor-treated (E) and PLC $\gamma$ inhibitor-treated (F) embryos had 'side-by-side' vessels (arrows), indicating overriding aorta or DORV. (G-I) Cross-sections through hearts in D-F and stained with Hematoxylin and Eosin. The aorta was in a sideby-side orientation with the pulmonary trunk in the MEK inhibitortreated $(\mathrm{H})$ and the PLC $\gamma$ inhibitor-treated $(\mathrm{I})$ animals. (J-L) Hearts from day 9 embryos after neural crest ablation alone (J) or neural crest ablation (NCA) followed by treatment with the MEK inhibitor (K) or PLC $\gamma$ inhibitor (L). All of the hearts from the NCA embryos had a common outlet (PTA).

inhibitors were also able to rescue arterial pole alignment but not septation in $43 \%$ of the neural crest-ablated embryos treated with the MEK inhibitor $(n=7)$ and $38 \%$ of the neural crest-ablated embryos treated with the PLC $\gamma$ inhibitor $(n=8)$. The day 9 hearts from the inhibitor-treated embryos had the aortic side of the common outlet (PTA) in its normal position behind the pulmonary region of the outlet, unlike the outflow in neural crest-ablated embryos in which the aortic a pulmonary regions of the outlet are in a side-by-side orientation similar to what is seen in DORV (Fig. 6 , compare $\mathrm{J}$ with $\mathrm{K}$ and $\mathrm{L}$ ). Although this rescue of alignment is less frequent, it does suggest that normalization of differentiation or proliferation in the SHF by the MEK or PLC inhibitors in the neural crest-ablated embryos is sufficient to restore outflow alignment. 

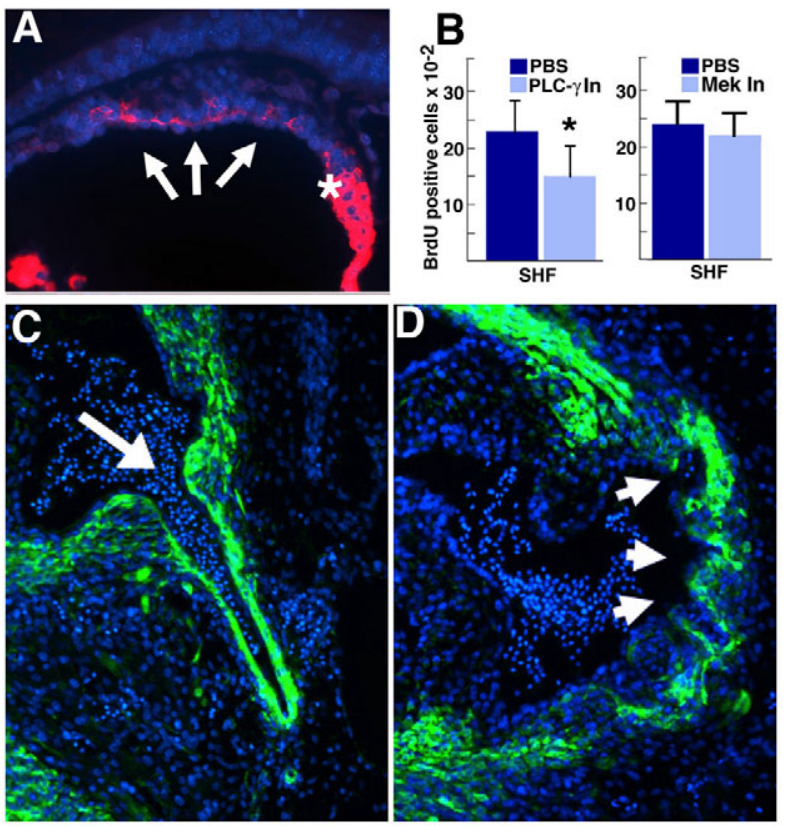

Fig. 7. MEK and PLC $\gamma$ inhibitors disrupt development of the SHF. (A) Inhibition of Ras/Erk signaling with the Mek inhibitor caused premature myocardial differentiation in the SHF. A HH16 embryo, sagittally sectioned through outflow tract and SHF, was immunostained for MF20 (red) to mark myocardium and Hoechst to label the nuclei. The MF20 was ectopically expressed in the SHF mesoderm (arrows) that is continuous with the myocardial rim (asterisk) of the outflow tract. (B) Graph showing the number of proliferating cells in the SHF of embryos treated with the PLC $\gamma$ and MEK inhibitors compared with control embryos. Only inhibition of the PLC $\gamma$ pathway significantly decreased SHF proliferation ( ${ }^{*} P=0.03$ ). (C,D) Mek inhibitor treatment disrupted development of the coronary stems. Cross-section through the base of aorta at the left coronary stem insertion from a control embryo (C) and an embryo treated with the MEK inhibitor (D) and stained with SM22. Arrow in $C$ shows normal single coronary stem. Arrows in $\mathrm{D}$ show the abnormal and multiple small vessels traversing the aortic wall.

\section{Inhibition of Ras/Erk pathway causes premature myocardial differentiation in the SHF while inhibition of PLC- $\gamma$ pathway decreases SHF proliferation in vivo}

Examination of the SHF in MEK inhibitor-treated embryos showed the presence of scattered ectopic MF20-positive cells in the progenitor population (four out of six embryos, Fig. 7A). No ectopic patches of differentiated myocardium were observed in the control or the PLC $\gamma$-treated chicks. This premature differentiation corresponds to our in vitro data showing that MEK inhibition promotes myocardial differentiation. There was no alteration in proliferation in these embryos (Fig. 7B).

By contrast, inhibition of the PLC $\gamma$ pathway caused decreased SHF proliferation $(P=0.03)$ in HH16 embryos (Fig. 7B). These results support the in vitro data showing that the PLC $\gamma$ pathway regulates proliferation in the SHF explants. Furthermore, the arterial pole defects observed at day 9 are probably due to disrupted SHF development, albeit by two different mechanisms. Premature differentiation or decreased proliferation of SHF progenitors would result in a smaller pool of progenitors able to contribute myocardium and smooth muscle to the arterial pole.

\section{Inhibition of Ras/Erk intracellular signaling disrupts coronary artery patterning}

Coronary vascular smooth muscle is derived from two distinct cell lineages: epicardially derived cells provide the majority of vascular smooth muscle (Dettman et al., 1998; Mikawa and Gourdie, 1996) and the SHF provides the vascular smooth muscle of the coronary stems at the base of the aorta (Sun et al., 2007). Coronary artery patterning defects were observed in hearts of embryos treated with the MEK inhibitor. Coronary vessels were present throughout the ventricular myocardium, but presence and size of the right and left coronary stems was variable. In the chick, coronary stems are established by incubation day 7 (Waldo et al., 1994). We noted that the presence and size of the right and left coronary stems was variable in hearts of embryos treated with MEK inhibitor. The stems were tiny with several small vessels inserting into the wall of the aorta that never coalesced into a vessel of significant size (Fig. 7D). This mispatterning was similar to the immature stages of coronary patterning (Waldo et al., 1994) and comparable with the defects seen after SHF ablation (Ward et al., 2005). The vascular smooth muscle of the coronary stems and some regions of the vascular smooth muscle at the base of the aorta and pulmonary artery were less well organized in the hearts of the MEK inhibitor-treated embryos (Fig. 7D). Thus, inhibition of Ras/Erk signaling disrupts the development of SHF-derived vascular smooth muscle progenitors.

\section{DISCUSSION}

This is the first demonstration that the SHF mesoderm represents a multipotent stem cell population. Pure mesodermal SHF explants spontaneously differentiate into beating myocardium, smooth muscle and endothelial cells. The myocardial and smooth muscle differentiation in explanted SHF follows the same developmental timeline as in vivo. Clonal analysis shows that there is a mixed population of progenitors within the SHF that have the potential to differentiate into the all three cardiovascular cell types. These results combined with the asymmetric localization of Numb, anchored by transitin, suggests the SHF contains a multipotent progenitor capable of self renewal.

Asymmetric division of stem cells occurs within restricted local niches or micro-environments (Gulino et al., 2010). These niches are thought to promote stem cell maintenance. Thus, one daughter cell will lie outside the niche and adopt a different cell fate from a cell residing in the niche. This allows segregation of 'determinants' asymmetrically in daughter cells, such that cell divisions may position daughter cells in different micro-environments. The asymmetric localization of Numb may promote distinct fates of progenitor cells by interacting with components of signaling pathways triggered by specific factors in the niche. How and what factors interact with Numb to trigger the cell fate choice are not fully understood. Studies in invertebrate and vertebrate systems suggest the involvement of asymmetric cell division in fate determination of neural progenitors. Fate determinants in Drosophila, such as Numb and Prospero, are asymmetrically localized in neuroblasts during mitosis (for a review, see Gulino et al., 2010). The daughter cell that receives Prospero and Numb differentiates into a ganglion mother cell, whereas the daughter cell without Prospero and Numb remains as a neuroblast. Numb has also been shown to regulate neurogenesis in mouse embryos (Zhong et al., 2000; Zilian et al., 2001; Peterson et al., 2002; Li et al., 2003). Recent studies in chick have shown the requirement of the intermediate filament protein transitin for the proper intracellular localization of Numb in neural stem cells (Wakamatsu et al., 2007). Disruption of transitin expression by RNAi inhibited proliferation and promoted neuronal differentiation. Asymmetric Numb localization 
has also been shown to be important in invertebrate cardiogenesis but little is known about Numb and vertebrate carcinogenesis. Studies in Drosophila cardiac mesoderm progenitors showed that progenitors of differing cell lineages adopt a myocardial cell fate, as opposed to a pericardial fate, when cell division is inhibited. Interestingly, however, these progenitors adopt a pericardial cell fate when cell division is blocked in Numb mutants or in embryos with constitutive Notch activity (Han and Bodmer, 2003).

Proliferation and differentiation signals must be tightly regulated in order maintain the progenitor population that will produce the various cells to form the arterial pole. Our studies show that FGF and BMP signaling act as opposing signaling cues that regulate the development of the SHF cells. FGF8 signaling is required to maintain the SHF in a proliferative undifferentiated state whereas BMP is a strong myocardial differentiation signal. In addition, FGF can abrogate BMP-induced differentiation most likely in a concentration-dependent manner. FGF signaling is interpreted intracellularly via RAS/Erk-dependent and -independent pathways. Using specific inhibitors, we show that the Ras/Erk pathway inhibits myocardial differentiation, whereas the PLC $\gamma$ and PI3K pathways promote proliferation. Interestingly, although FGF8 inhibits myocardial differentiation it promotes smooth muscle differentiation in SHF explants in a Ras/Erk pathway-dependent manner. The importance of the FGF Ras-dependent and -independent pathways in arterial pole development was confirmed by disrupting these pathways in vivo, which led to arterial pole alignment and coronary stem defects.

Previously, it has not been clear whether the SHF contained cells that were predetermined or were already specified to the myocardial or smooth muscle lineage. The existence of a multipotent cardiovascular progenitor has been identified in murine ES cells and the embryonic heart based on cardiac transcription factor profiling (Chen et al., 2009; Moretti et al., 2006; Wu et al., 2006). We have identified a multipotent progenitor in isolated SHF mesoderm. This, combined with the asymmetric expression of Numb, leads us to postulate that the SHF is a source of cardiac stem cells. This is further supported by our results in which we show that the progenitors are not specified to a particular cell lineage because we can manipulate the amount myocardial and smooth muscle differentiation with BMP or FGF signaling.

The role of BMP and FGF signaling in endothelial differentiation remains unclear as is the origin of endocardium in vivo. Studies in chick support the existence of distinct progenitor cell populations within the primitive streak for myocardium and endocardium prior to their migration into the cardiogenic mesoderm (Coffin and Poole, 1988). Using retroviral labeling at the time of gastrulation, Cohen-Gould and Mikawa found no simultaneously labeled endocardial and myocardial cells at the linear heart tube stage (Cohen-Gould and Mikawa, 1996). Taken together, these studies support an early separation of endocardial and myocardial lineages in the developing chick heart, most likely prior to or during gastrulation. However, these studies were not continued beyond $\mathrm{HH} 10$, which is nearly 24 hours earlier than the stage at which the SHF was isolated for the present studies; thus, it is possible that the SHF contributes endocardial cells to the heart.

Many studies have shown that FGF and BMP pathways interact positively or negatively in development. Brief application of both BMP2 and FGF4 can induce cardiomyocyte differentiation in a few cells from non-cardiogenic mesoderm, but all explants can be forced to differentiate by brief FGF4 treatment followed by continuous BMP2 treatment (Barron et al., 2000). This suggests that a balance of BMP and FGF signaling is required to promote cardiomyocyte differentiation from cardiac progenitors. Studies in the chick have shown that BMP signaling plays an early role in the specification of anterior heart field mesoderm into the cardiac, rather than the skeletal, muscle lineage (Tirosh-Finkel et al., 2006). A regulatory crosstalk between BMP and FGF signaling pathways within the anterior heart field niche is highlighted in the accompanying study by Tirosh-Finkel et al., demonstrating that BMP4 promotes cardiomyocyte differentiation by blocking FGF signaling (Tirosh-Finkel et al., 2010). This suggests that BMP and FGF signaling pathways act via inter- and intra-regulatory loops in multiple tissues, to coordinate the balance between proliferation and differentiation of cardiac progenitors. Mice with a targeted deletion of FGF8 in the anterior heart field Nkx2.5 domain have right ventricle and outflow tract defects and decreased BMP4 expression (Ilagan et al., 2006). Furthermore, targeted disruption of FGF8 in the second heart field and endoderm using a FGF8; IsllCre also resulted in outflow defects and decreased BMP2/4 expression (Park et al., 2008). These studies suggest that the second heart field and anterior heart field progenitors that include the smaller subregion of SHF progenitors are targets of FGF signaling and that FGF8 signaling may regulate BMP signaling. Recent studies suggest that there is direct intracellular crosstalk between Ras/Erk and BMP/Smad pathways at the level of the Smad1/5/8 (Sapkota et al., 2007). Ras-activated kinases can phosphorylate a linker region on Smad1 that targets Smad1 for degradation thereby depressing BMP signaling.

BMP signaling via R-Smads has been shown to regulate $\mathrm{Nkx} 2.5$ expression (Liberatore et al., 2002). A recent study has shown that Nkx2.5 influences cardiac progenitor cell proliferation through a Smad1-dependent negative-feedback loop, and that arterial pole alignment defects in mice hypomorphic for $\mathrm{Nkx} 2.5$ could be rescued by deleting Smad1 in the Nkx2.5 expression domain (Prall et al., 2007). These studies show that in Nkx2.5 coordinates periods of induction of cardiac progenitors, proliferation of the progenitors and arterial pole morphogenesis through a Smad1-dependent negative-feedback loop. Our findings also give FGF signaling a role in maintaining proliferation of the SHF progenitors and inhibiting differentiation of myocardial cells.

What role the Nkx2.5/ BMP signaling axis plays in arterial pole smooth muscle is largely unknown. Interestingly, mice heterozygous for targeted deletion of FGF8 within the Tbx1 domain (which is also expressed in the SHF) have decreased vascular smooth muscle differentiation at the arterial pole (Brown et al., 2004). The studies presented here suggest that FGF signaling promotes smooth muscle differentiation within the SHF progenitor cells. There are two potential explanations for this: either the Erk pathway promotes maintenance of an uncommitted progenitor that over time loses myocardial potential; or the pathway is directly inhibiting myocardial fates and promoting smooth muscle fates. We favor the former because we have not significantly shortened the smooth muscle differentiation timeline. The disruption of coronary artery patterning further supports a role of the Ras-dependent pathways in differentiation of SHF-derived smooth muscle. It is possible and likely that the junction of cardiac neural crest-derived smooth muscle with SHF-derived smooth muscle is altered. Whether there is a direct induction of smooth fates by FGF8 or induction is secondary to some other signaling event will be the subject of further studies.

\section{Acknowledgements}

We thank H. A. Stadt, K. Pegram, A. M. Scholl, S. Anwar and J. Newton for technical assistance. Supported by NIH grants HL036059, HL070140, HL083240 and American Heart Association grant AHA0830464N. Deposited in PMC for release after 12 months. 
Competing interests statement

The authors declare no competing financial interests.

\section{Supplementary material}

Supplementary material for this article is available at

http://dev.biologists.org/lookup/suppl/doi:10.1242/dev.051565/-/DC1

\section{References}

Abu-Issa, R. and Kirby, M. L. (2007). Heart field: from mesoderm to heart tube Annu. Rev. Cell Dev. Biol. 23, 45-68.

Abu-Issa, R., Smyth, G., Smoak, I., Yamamura, K.-I. and Meyers, E. (2002). Fgf8 is required for pharyngeal arch and cardiovascular development in the mouse. Development 129, 4613-4625.

Barron, M., Gao, M. and Lough, J. (2000). Requirement for BMP and FGF signaling during cardiogenic induction in non-precardiac mesoderm is specific, transient, and cooperative. Dev. Dyn. 218, 383-393.

Brown, C. B., Wenning, J. M., Lu, M. M., Epstein, D. J., Meyers, E. N. and Epstein, J. A. (2004). Cre-mediated excision of Fgf8 in the Tbx1 expression domain reveals a critical role for Fgf8 in cardiovascular development in the mouse. Dev. Biol. 267, 190-202.

Cai, C. L., Liang, X., Shi, Y., Chu, P. H., Pfaff, S. L., Chen, J. and Evans, S. (2003). Isl1 identifies a cardiac progenitor population that proliferates prior to differentiation and contributes a majority of cells to the heart. Dev. Cell 5, 877889.

Chen, L., Fulcoli, F. G., Tang, S. and Baldini, A. (2009). Tbx1 regulates proliferation and differentiation of multipotent heart progenitors. Circ. Res. 105 842-851.

Coffin, D. J. and Poole, T. J. (1988). Embryonic vascular development: immunohistochemical identification of the origin and subsequent morphogenesis of the major vessel primordia in quail embryos. Development 102, 735-748.

Cohen-Gould, L. and Mikawa, T. (1996). The fate diversity of mesodermal cells within the heart field during chicken early embryogenesis. Dev. Biol. 177, 265273.

Creemers, E. E., Sutherland, L. B., Oh, J., Barbosa, A. C. and Olson, E. N. (2006). Coactivation of MEF2 by the SAP domain proteins myocardin and MASTR. Mol. Cell 23, 83-96.

Dettman, R. W., Denetclaw, W., Jr, Ordahl, C. P. and Bristow, J. (1998) Common epicardial origin of coronary vascular smooth muscle, perivascular fibroblasts, and intermyocardial fibroblasts in the avian heart. Dev. Biol. 193 169-181

Dyer, L. A. and Kirby, M. L. (2009a). Sonic hedgehog maintains proliferation in secondary heart field progenitors and is required for normal arterial pole formation. Dev. Biol. 330, 305-317.

Dyer, L. A. and Kirby, M. L. (2009b). The role of secondary heart field in cardiac development. Dev. Biol. 336, 137-144.

Farrell, M. J., Burch, J. L., Wallis, K., Rowley, L., Kumiski, D., Stadt, H., Godt, R. E., Creazzo, T. L. and Kirby, M. L. (2001). FGF-8 in the ventral pharynx alters development of myocardial calcium transients after neural crest ablation. J. Clin. Invest. 107, 1509-1517.

Frank, D., Fotheringham, L., Brewer, J., Muglia, L., Tristani-Firouzi Capecchi, M. and Moon, A. (2002). An Fgf8 mouse mutant phenocopies human 22q11 deletion syndrome. Development 129, 4591-4603.

Grimes, A. C., Stadt, H. A., Shepherd, I. T. and Kirby, M. L. (2006). Solving an enigma: arterial pole development in the zebrafish heart. Dev. Biol. 290, 265276.

Gulino, A., Di Marcotullio, L. and Screpanti, I. (2010). The multiple functions of Numb. Exp. Cell Res. 316, 900-906.

Hamburger, V. and Hamilton, H. L. (1951). A series of normal stages in the development of the chick embryo. J. Morphol. 88, 49-92.

Han, Z. and Bodmer, R. (2003). Myogenic cells fates are antagonized by Notch only in asymmetric lineages of the Drosophila heart, with or without cell division. Development 130, 3039-3051.

Hutson, M. R., Zhang, P., Stadt, H. A., Sato, A., Li, Y.-X., Burch, J., Creazzo, T. L. and Kirby, M. L. (2006). Cardiac arterial pole alignment is sensitive to FGF8 signaling in the pharynx. Dev. Biol. 295, 486-497.

llagan, R., Abu-Issa, R., Brown, D., Yang, Y. P., Jiao, K., Schwartz, R. J., Klingensmith, J. and Meyers, E. N. (2006). Fgf8 is required for anterior heart field development. Development 133, 2435-2445.

Kattman, S. J., Huber, T. L. and Keller, G. M. (2006). Multipotent flk-1+ cardiovascular progenitor cells give rise to the cardiomyocyte, endothelial, and vascular smooth muscle lineages. Dev. Cell 11, 723-732.

Kojima, H., Nakatsubo, N., Kikuchi, K., Kawahara, S., Kirino, Y., Nagoshi, H., Hirata, Y. and Nagano, T. (1998). Detection and imaging of nitric oxide with novel fluorescent indicators: diaminofluoresceins. Anal. Chem. 70, 24462453

Li, H. S., Wang, D., Shen, Q., Schonemann, M. D., Gorski, J. A., Jones, K. R., Temple, S., Jan, L. Y. and Jan, Y. N. (2003). Inactivation of Numb and
Numblike in embryonic dorsal forebrain impairs neurogenesis and disrupts cortical morphogenesis. Neuron 40, 1105-1118.

Liberatore, C. M., Searcy-Schrick, R. D., Vincent, E. B. and Yutzey, K. E. (2002). Nkx-2.5 gene induction in mice is mediated by a smad consensus regulatory region. Dev. Biol. 244, 243-256.

Meilhac, S. M., Esner, M., Kelly, R. G., Nicolas, J. F. and Buckingham, M. E. (2004). The clonal origin of myocardial cells in different regions of the embryonic mouse heart. Dev. Cell 6, 685-698

Mikawa, T. and Gourdie, R. G. (1996). Pericardial mesoderm generates a population of coronary smooth muscle cells migrating into the heart along with ingrowth of the epicardial organ. Dev. Biol. 174, 221-232.

Moretti, A., Caron, L., Nakano, A., Lam, J. T., Bernshausen, A., Chen, Y. Qyang, Y., Bu, L., Sasaki, M., Martin-Puig, S. et al. (2006). Multipotent embryonic is $1+$ progenitor cells lead to cardiac, smooth muscle, and endothelial cell diversification. Cell 127, 1151-1165.

Nakatsubo, N., Kojima, H., Kikuchi, K., Nagoshi, H., Hirata, Y., Maeda, D. Imai, Y., Irimura, T. and Nagano, T. (1998). Direct evidence of nitric oxide production from bovine aortic endothelial cells using new fluorescence indicators: diaminofluoresceins. FEBS Lett. 427, 263-266.

Park, E. J., Ogden, L. A., Talbot, A., Evans, S., Cai, C. L., Black, B. L., Frank, D. U. and Moon, A. M. (2006). Required, tissue-specific roles for Fgf8 in outflow tract formation and remodeling. Development 133, 2419-2433.

Park, E. J., Watanabe, Y., Smyth, G., Miyagawa-Tomita, S., Meyers, E. Klingensmith, J., Camenisch, T., Buckingham, M. and Moon, A. M. (2008). An FGF autocrine loop initiated in second heart field mesoderm regulates morphogenesis at the arterial pole of the heart. Development $\mathbf{1 3 5}$, 3599-3610

Petersen, P. H., Zou, K., Hwang, J. K., Jan, Y. N. and Zhong, W. (2002) Progenitor cell maintenance requires numb and numblike during mouse neurogenesis. Nature 419, 929-934.

Prall, O. W., Menon, M. K., Solloway, M. J., Watanabe, Y., Zaffran, S., Bajolle, F., Biben, C., McBride, J. J., Robertson, B. R., Chaulet, H. et al. (2007). An Nkx2-5/Bmp2/Smad1 negative feedback loop controls heart progenitor specification and proliferation. Cell 128, 947-959.

Sapkota, G., Alarcon, C., Spagnoli, F. M., Brivanlou, A. H. and Massague, J. (2007). Balancing BMP signaling through integrated inputs into the Smad1 linker. Mol. Cell 25, 441-454

Schlange, T., Andre, B., Arnold, H. H. and Brand, T. (2000). BMP2 is required for early heart development during a distinct time period. Mech. Dev. 91, 259270.

Schneider, V. A. and Mercola, M. (2001). Wnt antagonism initiates cardiogenesis in Xenopus laevis. Genes Dev. 15, 304-315

Schultheiss, T. M., Burch, J. B. E. and Lassar, A. B. (1997). A role for bone morphogenetic proteins in the induction of cardiac myogenesis. Genes Dev. 11, 451-462.

Somi, S., Buffing, A. A. M., Moorman, A. F. M. and Van Den Hoff, M. J. B. (2004). Dynamic patterns of expression of BMP isoforms 2, 4, 5, 6, and 7 during chicken heart development. Anat. Rec. 279, 636-651.

Sun, Y., Liang, X., Najafi, N., Cass, M., Lin, L., Cai, C. L., Chen, J. and Evans, S. M. (2007). Islet 1 is expressed in distinct cardiovascular lineages, including pacemaker and coronary vascular cells. Dev. Biol. 304, 286-296.

Tirosh-Finkel, L., Elhanany, H., Rinon, A. and Tzahor, E. (2006). Mesoderm progenitor cells of common origin contribute to the head musculature and the cardiac outflow tract. Development 133, 1943-1953.

Tirosh-Finkel, L., Zeisel, A., Brodt-Ivenshitz, M., Shamai, A., Yao, Z., Seger, R., Domany, E. and Tzahor, E. (2010). BMP-mediated inhibition of FGF signaling promotes cardiomyocyte differentiation of anterior heart field progenitors. Development 137, 2989-3000

Verzi, M. P., McCulley, D. J., De Val, S., Dodou, E. and Black, B. L. (2005). The right ventricle, outflow tract, and ventricular septum comprise a restricted expression domain within the secondary/anterior heart field. Dev. Biol. 287, 134 145.

Wakamatsu, Y., Nakamura, N., Lee, J. A., Cole, G. J. and Osumi, N. (2007) Transitin, a nestin-like intermediate filament protein, mediates cortical localization and the lateral transport of Numb in mitotic avian neuroepithelial cells. Development 134, 2425-2433.

Waldo, K. L., Kumiski, D. H. and Kirby, M. L. (1994). Association of the cardiac neural crest with development of the coronary arteries in the chick embryo. Anat. Rec. 239, 315-331.

Waldo, K. L., Kumiski, D. and Kirby, M. L. (1996). Cardiac neural crest is essential for the persistence rather than the formation of an arch artery. Dev. Dyn. 205, 281-292.

Waldo, K. L., Kumiski, D. H., Wallis, K. T., Stadt, H. A., Hutson, M. R., Platt, D. H. and Kirby, M. L. (2001). Conotruncal myocardium arises from a secondary heart field. Development 128, 3179-3188.

Waldo, K. L., Hutson, M. R., Ward, C. C., Zdanowicz, M., Stadt, H. A., Kumiski, D., Abu-Issa, R. and Kirby, M. L. (2005). Secondary heart field contributes myocardium and smooth muscle to the arterial pole of the developing heart. Dev. Biol. 281, 66-77. 
Ward, C., Stadt, H. A., Hutson, M. R. and Kirby, M. L. (2005). Ablation of the secondary heart field leads to tetralogy of Fallot and pulmonary atresia. Dev. Biol. 284, 72-83.

Watanabe, Y., Miyagawa-Tomita, S., Vincent, S. D., Kelly, R. G., Moon, A. M. and Buckingham, M. E. (2010). Role of mesodermal FGF8 and FGF10 overlaps in the development of the arterial pole of the heart and pharyngeal arch arteries. Circ. Res. 106, 495-503.

Wu, S. M., Fujiwara, Y., Cibulsky, S. M., Clapham, D. E., Lien, C.-I., Schultheiss, T. M. and Orkin, S. H. (2006). Developmental origin of a bipotential myocardial and smooth muscle cell precursor in the mammalian heart. Cell 127, 1137-1150.

Xu, H., Morishima, M., Wylie, J. N., Schwartz, R. J., Bruneau, B. G., Lindsay, E. A. and Baldini, A. (2004). Tbx1 has a dual role in the morphogenesis of the cardiac outflow tract. Development 131, 3217-3227.
Yelbuz, T. M., Waldo, K. L., Kumiski, D. H., Stadt, H. A., Wolfe, R. R., Leatherbury, L. and Kirby, M. L. (2002). Shortened outflow tract leads to altered cardiac looping after neural crest ablation. Circulation 106, 504510.

Yelbuz, T. M., Waldo, K. L., Zhang, X. W., Zdanowicz, M., Parker, J., Creazzo, T. L., Johnson, G. A. and Kirby, M. L. (2003). Myocardial volume and organization are changed by failure of addition of secondary heart field myocardium to the cardiac outflow tract. Dev. Dyn. 228, 152-160.

Zhong, W., Jiang, M. M., Schonemann, M. D., Meneses, J. J., Pedersen, R. A., Jan, L. Y. and Jan, Y. N. (2000). Mouse numb is an essential gene involved in cortical neurogenesis. Proc. Natl. Acad. Sci. USA 97, 6844-6849.

Zilian, O., Saner, C., Hagedorn, L., Lee, H. Y., Sauberli, E., Suter, U., Sommer, L. and Aguet, M. (2001). Multiple roles of mouse Numb in tuning developmental cell fates. Curr. Biol. 11, 494 -501. 